\title{
Debris-flow forecasting at regional scale by combining susceptibility mapping and radar rainfall
}

\author{
M. Berenguer ${ }^{1}$, D. Sempere-Torres ${ }^{1}$, and M. Hürlimann ${ }^{2}$ \\ ${ }^{1}$ Center of Applied Research in Hydrometeorology, Technical University of Catalonia, Barcelona, Spain \\ ${ }^{2}$ Department of Geotechnical Engineering and Geosciences, Technical University of Catalonia, Barcelona, Spain
}

Correspondence to: M. Berenguer (marc.berenguer@ crahi.upc.edu)

Received: 13 September 2014 - Published in Nat. Hazards Earth Syst. Sci. Discuss.: 6 October 2014

Revised: 20 January 2015 - Accepted: 24 February 2015 - Published: 13 March 2015

\begin{abstract}
This work presents a technique for debris-flow (DF) forecasting able to be used in the framework of DF early warning systems at regional scale. The developed system is applied at subbasin scale and is based on the concepts of fuzzy logic to combine two ingredients: (i) DF subbasin susceptibility assessment based on geomorphological variables and (ii) the magnitude of the rainfall situation as depicted from radar rainfall estimates. The output of the developed technique is a three-class warning ("low", "moderate" or "high") in each subbasin when a new radar rainfall map is available.

The developed technique has been applied in a domain in the eastern Pyrenees (Spain) from May to October 2010. The warning level stayed "low" during the entire period in $20 \%$ of the subbasins, while in the most susceptible subbasins the warning level was at least "moderate" for up to 10 days.

Quantitative evaluation of the warning level was possible in a subbasin where debris flows were monitored during the analysis period. The technique was able to identify the three events observed in the catchment (one debris flow and two hyperconcentrated flow events) and produced no false alarm.
\end{abstract}

\section{Introduction}

Intense and/or prolonged precipitation is the main agent triggering mass movement hazards like landslides and debris flows (DF). These phenomena result in loss of life and goods in mountainous areas. During the last 2-3 decades, there has been a tendency towards increasing the number of operational landslide and DF early warning systems (EWSs, see the reviews of Wilson, 2004; Egashira, 2007; Alfieri et al., 2012). These have experienced an evolution from very local systems implemented in the most sensitive areas to systems designed for regional and national scales; notable examples are the Japanese DF EWS (Osanai et al., 2010) and the Hong Kong landslide EWS (Chen and Lee, 2004), as well as some regional systems in Italy (Aleotti, 2004), Brazil (Ortigao and Justi, 2004), Canada (Jakob et al., 2006), New Zealand (Keys and Green, 2008), Taiwan (Kung et al., 2008) and the USA (Wilson, 2004; Baum and Godt, 2010). In Europe, the Flood Directive 2007/60/EC (EC, 2007) prompts member states to review their current risk management, and points at early warning systems as an essential part of effective preparedness for natural disasters induced by precipitation.

In EWSs, hazard assessment for rainfall-induced DFs (either triggered by landslides or by erosion and material entrainment into the flow) is based on combining (i) information about DF susceptibility in the area under consideration and (ii) measurements and forecasts of rainfall (see e.g., Hong and Adler, 2007).

DF susceptibility assessment is usually performed by relating the occurrence of DF with a number of variables controlling DF initiation to identify the locations more prone to future events. In general, it is agreed that including detailed information of these variables leads to improved DF susceptibility assessment. However, the availability of very high-resolution information of certain variables at regional scale is limited and, consequently, susceptibility mapping at these scales is based on simplified approaches. Several of these variables are based on GIS-retrieved watershed morphometrics derived from digital elevation models (DEMs) 


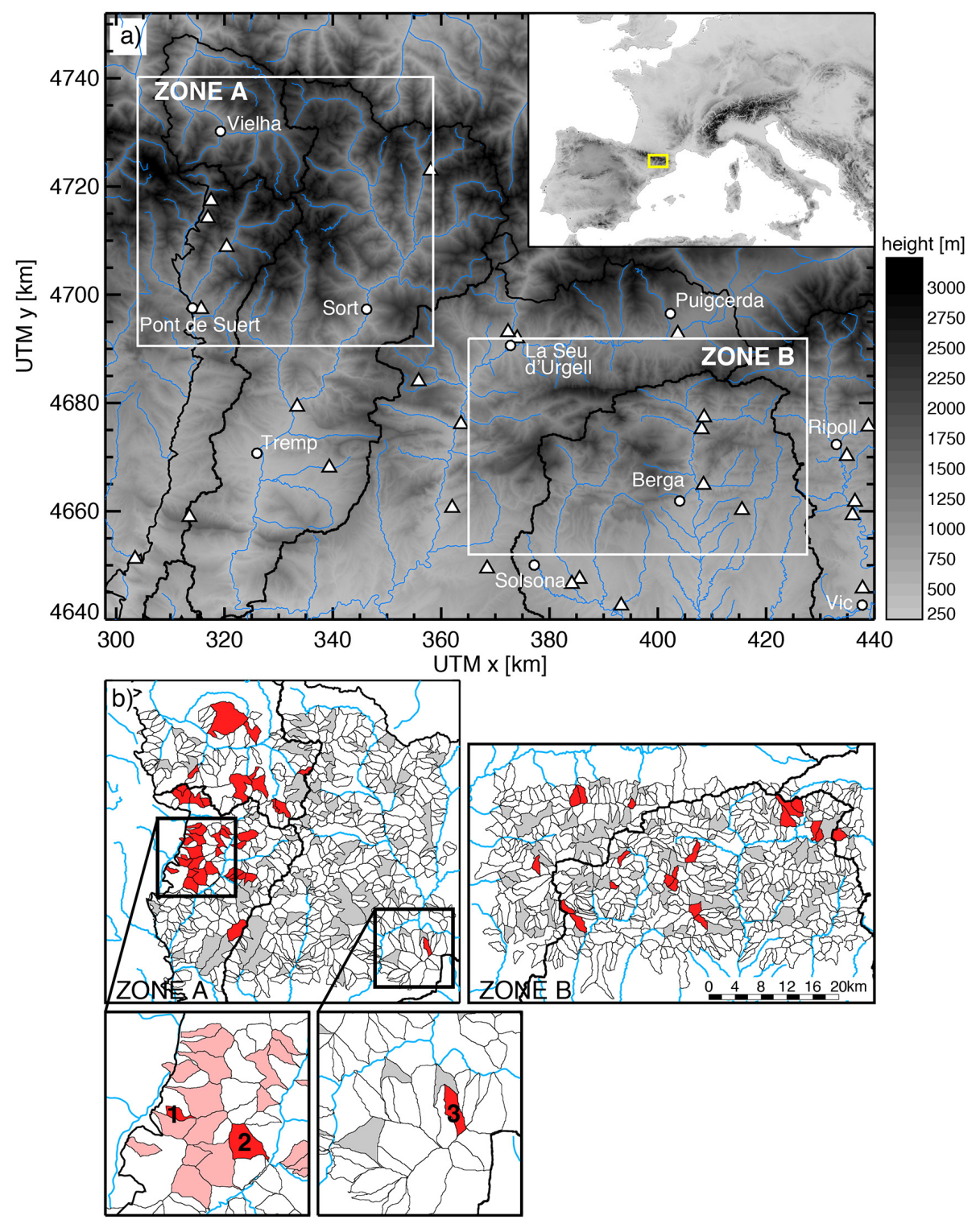

Figure 1. Study area: (a) the two white rectangles in the main panel show the two subdomains where the EWS has been implemented (zones A and B). The circles indicate the location of the main municipalities, and the triangles show the location of the available rain gauges. (b) Subdivision of zones A and B in subbasins for the implementation of the system. The first and second order subbasins are indicated in white and grey, respectively. Analysis of aerial photos detected traces of DFs in the red-shaded subbasins. In the two bottom left sub-panels, the numbers correspond to subbasins (1) Rebaixader $\left(0.7 \mathrm{~km}^{2}\right),(2)$ Erill $\left(3.1 \mathrm{~km}^{2}\right)$ and (3) Port Ainé $\left(1.9 \mathrm{~km}^{2}\right)$.

and sometimes include more specific geological or soil information (e.g., Lee and Min, 2001; He et al., 2003; Ayalew et al., 2004; Marchi and Dalla Fontana, 2005; Lee, 2007; Sterlacchini et al., 2011; Chevalier et al., 2013).

Rainfall inputs are another fundamental element of DF EWSs. Alfieri et al. (2012) give an extensive review of the benefits and limitations of the different rainfall inputs used in the context of EWSs. DFs are very small-scale phenomena frequently triggered by rainfall extremes (for example due to stationary convective thunderstorms) at scales that are generally not well resolved by numerical weather prediction
(NWP) models or low-resolution rain gauge networks. As an alternative, radar rainfall measurements depict the rainfall with a resolution of the order of $1 \mathrm{~km}$ and $5 \mathrm{~min}$, which is better adapted to DF hazard monitoring (as stated, e.g., by Ben David-Novak et al., 2004) especially in the context of regional EWSs.

The magnitude of the rainfall situation (i.e., its potential to trigger shallow landslides or DFs) is, in many cases, assessed by comparison of event rainfall with a critical rainfall threshold. These thresholds are frequently obtained for different event durations and computed (i) based on statistical analy- 
ses of regional records (e.g., Aleotti, 2004; Guzzetti et al., 2008; Brunetti et al., 2010) or (ii) using simplified dynamic approaches (e.g., Iverson, 2000; Papa et al., 2013).

Our area of study is in the central-eastern Pyrenees, where landslides and DFs are common processes. There are several case studies (e.g., Corominas and Santacana, 2003; Hürlimann et al., 2008; Medina et al., 2008; Portilla et al., 2010), and works focusing on landslide susceptibility (e.g., Santacana et al., 2003; Chevalier et al., 2013) and hazard assessment at local scale (Corominas et al., 2003; Hürlimann et al., 2006).

The main objective of this work was to develop a technique for DF warning that can be used in the framework of an operational EWS. The developed approach has been designed to fulfill the following conditions:

- Real-time operation at regional scale: to keep the computational cost of the technique into reasonable limits, we have divided our analysis domain into subbasins of less than $50 \mathrm{~km}^{2}$, where the warning level is determined. Radar-based rainfall inputs have been used to depict the evolution of the precipitation field over the domain.

- Simple outputs: the system has been designed to qualitatively assess DF hazard in all the subbasins of the monitored domain by issuing a three-class traffic-light code for warning levels "low", "moderate" and "high".

- Flexibility: the structure of the developed technique allows simple implementation in new study areas and integration of approaches to assess DF susceptibility or the magnitude of the rainfall situation alternative to those implemented in this study.

The paper is organized as follows: Sect. 2 describes the analysis domain. The method used for DF warning is introduced in Sect. 3. The results obtained during the warm season of 2010 are analyzed in Sect. 4, and, finally, concluding remarks are summarized in Sect. 5.

\section{Study area}

\subsection{Geomorphology and DF database}

The study has been carried out in two subdomains in the central-eastern Pyrenees (zones "A" and "B" in Fig. 1), over an area that covers about $2750 \mathrm{~km}^{2}$ and includes subcatchments in the Ter, Llobregat, Segre, Noguera Pallaresa, Noguera Ribagorçana and Garonne basins. The elevations of the study areas range between 400 and $3100 \mathrm{~m}$ a.s.l. The region has a Mediterranean-Alpine climate with mean yearly precipitation accumulations between 700 and $1200 \mathrm{~mm}$ and frequent high-intensity rainfall events. Chevalier (2013) divided the two analyzed subdomains into subbasins with the method of Strahler (1957) using the $5 \mathrm{~m} \times 5 \mathrm{~m}$ DEM produced by the Cartographic and Geological Institute of Catalonia. The drainage network was obtained with the D8 algorithm (O'Callaghan and Mark, 1984), and the definition of a stream uses a threshold of $1 \mathrm{~km}^{2}$ (further details can be found in Chevalier et al., 2013). The retrieved subdivision resulted in 896 first-order subbasins with areas between 1 and $13 \mathrm{~km}^{2}$ and 163 second-order subbasins between 2 and $45 \mathrm{~km}^{2}$. We have focused on first and second order subbasins (see Fig. 1) in principle more prone to the occurrence of DF events.

The analysis of the susceptibility of the subbasins to the occurrence of DF events is based on a number of geomorphological variables derived from the DEM. These variables have been related to the occurrence of DF in the subbasins of the analysis domain (see Sect. 3.1). This analysis has been done with the database set up by Chevalier (2013), who identified and georeferenced 56 reactive subbasins (i.e., with DF traces, see Fig. 1) from the analysis of aerial photographs (see also Chevalier et al., 2013).

\subsection{Rainfall estimates}

The rainfall data used in this study are radar quantitative precipitation estimate (QPE) maps of 30 min rainfall accumulations with a resolution of $1 \mathrm{~km}$. These maps have been produced with the Integrated Tool for Hydrometeorological Forecasting (EHIMI, Corral et al., 2009) from the volume scans of the Creu del Vent C-band Doppler radar of the Catalan Weather Service (located between 50 and $140 \mathrm{~km}$ south of the analysis domain; Fig. 2a). The EHIMI processing tool includes a chain of quality control and QPE algorithms, including (i) reduction of the effects of beam blockage by the orography using the algorithm of Delrieu et al. (1995), (ii) ground clutter elimination and substitution by combining the techniques of Sánchez-Diezma et al. (2001) and Berenguer et al. (2006), (iii) identification of the type of precipitation and extrapolation of elevated reflectivity measurements to the surface according to a double vertical profile of reflectivity as proposed by Franco et al. $(2006,2008)$ and (iv) conversion of reflectivity into rain rate using two $Z-R$ relationships: Marshall-Palmer's $Z=200 R^{1.6}$ for stratiform rain (Marshall and Palmer, 1948) and $Z=525 R^{1.28}$ for convective rain (Sempere-Torres et al., 1997). Finally, rainfall accumulations are obtained, accounting for the motion of the precipitation field and the evolution of rainfall intensities between consecutive instantaneous rainfall maps.

The analyzed period is the debris-flow season of 2010 from 1 May to 31 October. In the study area this was a rather wet period, with rainfall accumulations over $600 \mathrm{~mm}$ in some areas and without significant snow events. The comparison between radar rainfall estimates and rain gauge observations shows no systematic bias and a root mean square relative error of $15 \%$ for the 159 rain gauges within the radar coverage (Fig. 2). 


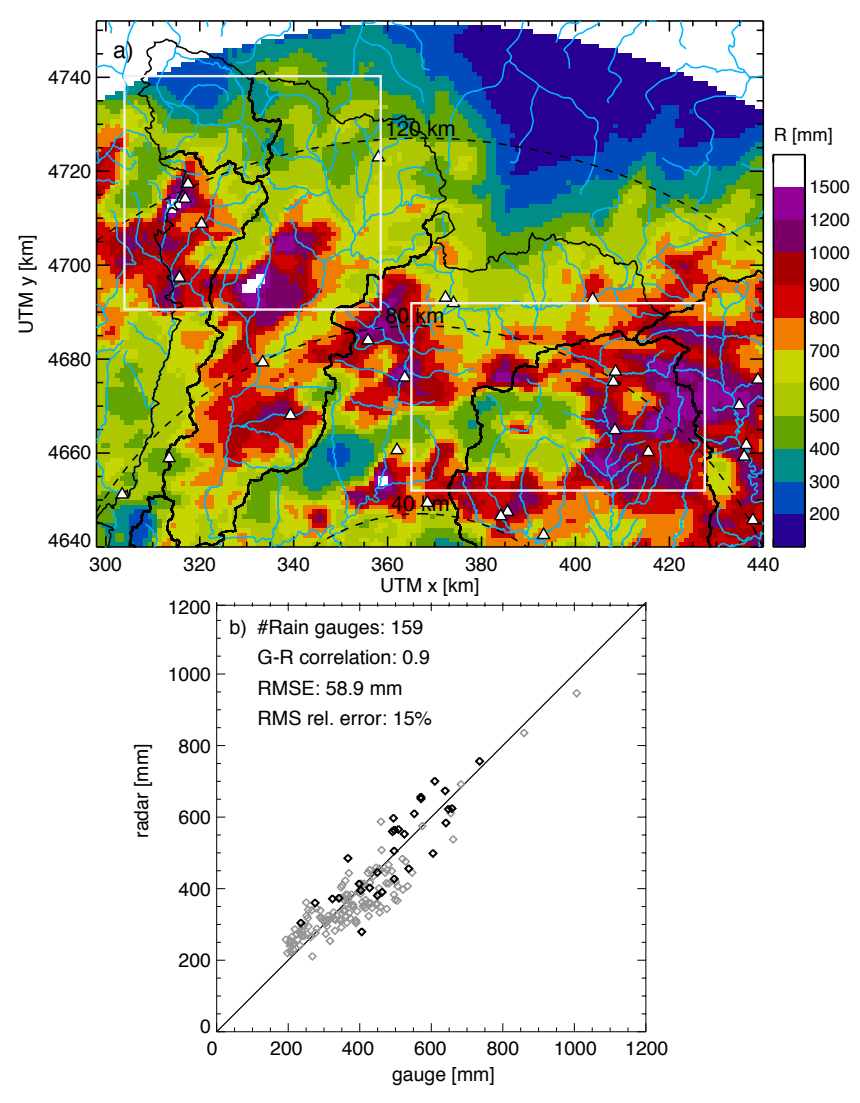

Figure 2. (a) Estimated rainfall accumulation for the period 1 May to 31 October 2010. The triangles indicate the location of the available rain gauges, and the black dashed lines are at constant distances from the Creu del Vent radar (40, 80 and $120 \mathrm{~km}$ ). (b) Scatterplot of radar rain gauge accumulations over the domain of the Creu del Vent radar (the pairs over the rain gauges within the domain of Fig. 1 are shown in black).

\section{DF forecasting}

The main goal of this work is to develop a flexible approach to classify DF warnings into three levels ("low", "moderate" and "high") at regional scale that can be implemented in real time in the framework of an EWS. The developed technique (a schematic diagram is shown in Fig. 3) is based on the concepts of fuzzy logic (e.g., Mendel, 1995) and consists of two independent components applied at subbasin scale to characterize

1. DF susceptibility based on geomorphologic variables (Sect. 3.1);

2. the magnitude of the rainfall situation as depicted from radar QPE (Sect. 3.2).

The combination of these two ingredients is done through a fuzzy rule to determine the warning level when a new radar QPE map is available.

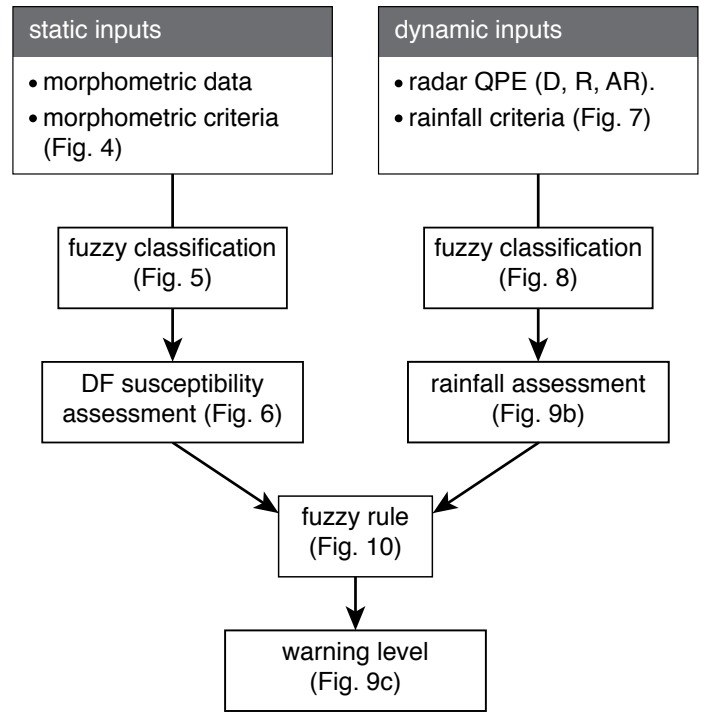

Figure 3. Schematic diagram of the proposed technique for DF warning at subbasin scale.

\subsection{DF susceptibility assessment}

The approach applied for assessing DF susceptibility is based on the relationship between geomorphological characteristics and the occurrence of DFs at subbasin scale. In the study area, Chevalier (2013) extracted 18 geomorphological variables from a DEM with GIS tools (the list of variables and how they were computed can be found in Chevalier et al., 2013). From this data set, we have analyzed the ability of the different variables to characterize DF occurrence. With this aim, the conditional probability distribution function (pdf) of each variable $X_{k}$ for reactive and non-reactive subbasins (i.e., where DF traces were and were not found, respectively) has been estimated as

$h_{k, r}(x)=p\left[X_{k}=x \mid R=r\right] \approx \frac{\#\left(X_{k}=x \cap R=r\right)}{\#(R=r)}$,

where $R$ stands for the subbasin type ( $r$ is either "reactive" or "non-reactive"), \# ( $\left.X_{k}=x \cap R=r\right)$ is the number of subbasins, in which $X_{k}=x$ and $R=r$, and $\#(R=r)$ is the number of subbasins where $R=r$.

The overlapping area between the pdf curves for nonreactive and reactive subbasins has been used to assess the skill of these geomorphological variables to discriminate between reactive and non-reactive subbasins. This is a very simple and intuitive criterion (also used by Cho et al., 2006, in a different context): the smaller the overlapping area for a given variable, the more skill it has to discriminate between reactive and non-reactive subbasins.

Among the 18 analyzed geomorphological variables, the subbasin maximum, mean and minimum heights (respectively, $h_{\text {max }}, h_{\text {mean }}$, and $\left.h_{\text {min }}\right)$, the mean slope $\left(s_{\text {mean }}\right)$ and the 

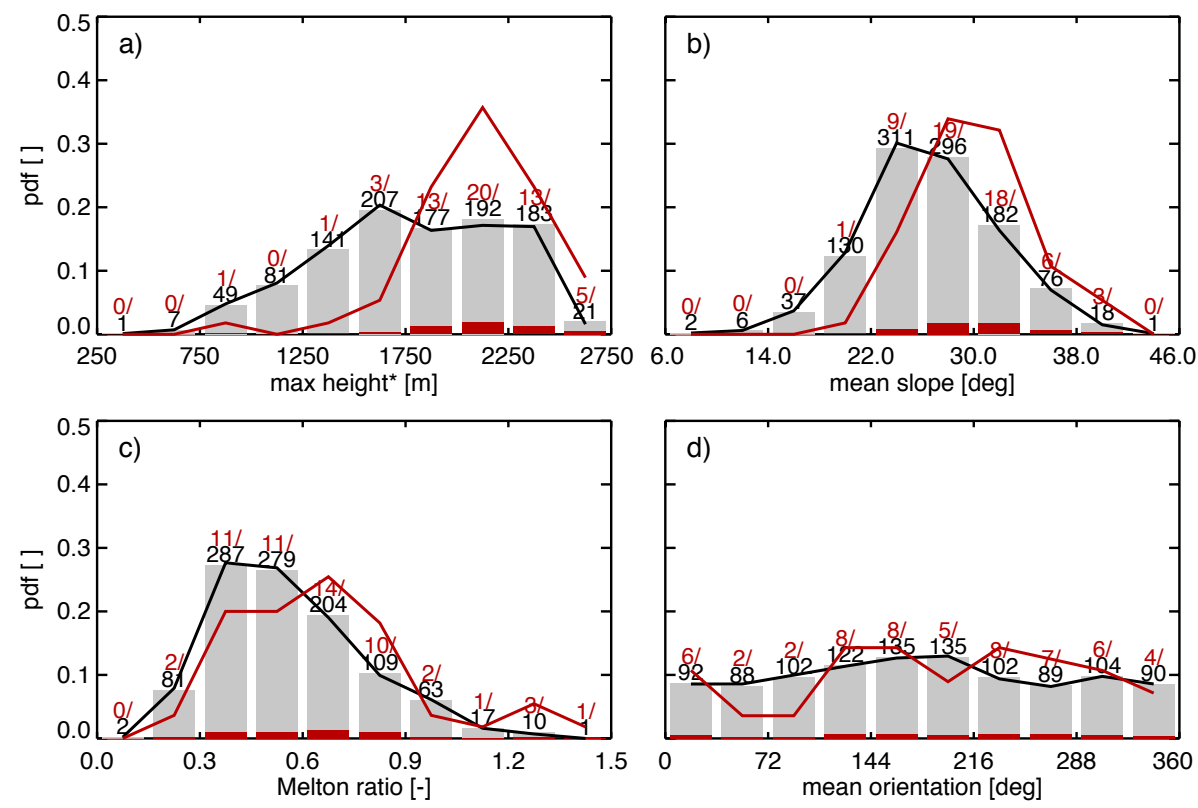

Figure 4. Histograms for the four geomorphological variables used for susceptibility assessment. (a) $\Delta h_{\max }$, (b) mean slope, (c) Melton ratio and (d) mean orientation of the subbasin. The red bars correspond to reactive subbasins. The black labels indicate the number of subbasins in each class (the red labels indicate the number of reactive subbasins). The lines show the probability distribution functions, $h_{k, r}(x)$, for non-reactive and reactive subbasins (black and red lines, respectively).

Melton ratio (MR) are the variables with the smallest overlapping areas, i.e., the most skillful for assessing the susceptibility of the subbasins (see the pdfs in Fig. 4). Similar results were found by Chevalier et al. (2013), based on more sophisticated data mining techniques over the same domain. Also, other authors (e.g., Bovis and Jakob, 1999; He et al., 2003; Lee, 2007) have reported the use of similar variables for susceptibility assessment.

To guarantee the independence of the variables, only one height variable has been used $\left(h_{\max }\right)$. Additionally, the mean orientation of the basin $\left(\theta_{\text {mean }}\right)$ has been included. This variable has a clear interest from the geophysical point of view, and other authors (e.g., Lee and Min, 2001; Ayalew et al., 2004) argued about its value to characterize DF susceptibility. The scatterplots for the pairs of the chosen variables $\left(h_{\text {max }}, s_{\text {mean }}\right.$, MR and $\left.\theta_{\text {mean }}\right)$ show that there is no clear dependence among them (the coefficient of determination among variables, $r^{2}$, is less than 0.25 ; Fig. 17 of Unzeta, 2012). Also, the separate pdfs for zones A and B show a clear resemblance, especially for $s_{\text {mean }}$ and MR. However, for $h_{\max }$ a shift of about $500 \mathrm{~m}$ is required to maximize the overlapping of the two pdfs. Because of this, $h_{\max }$ has been replaced with the new variable $\Delta h_{\max }=h_{\max }-\Delta$ (where $\Delta=500 \mathrm{~m}$ in zone A and $\Delta=0 \mathrm{~m}$ in zone B). In this way, the distribution of values of the chosen morphological variables can be well characterized with a single set of pdfs for the two domains (Fig. 4).

The four variables $\left(\Delta h_{\max }, s_{\text {mean }}\right.$, MR and $\left.\theta_{\text {mean }}\right)$ have been used to classify the subbasins in the analysis domain according to their susceptibility level in the categories "low", "medium" and "high". This is done in the framework of a fuzzy classifier that produces, for each subbasin, the membership degree to each of the three susceptibility classes. The membership degree is a value in the range $[0,1]$ that assesses the feasibility that the subbasin belongs to a certain class. This is done through a set of user-defined curves known as membership functions, $\mu_{k, s}(x)$, quantifying the expectation that a subbasin $i$ belongs to the susceptibility class $s$ (i.e., either "low", "moderate" or "high") provided that the variable $X_{k}$ takes a value $x_{i}$ in the subbasin; that is, $Y_{k, s}(i)=\mu_{k, s}\left(x_{i}\right)$. Finally, the membership degree $Y_{s}(i)$ for each of the three classes is obtained as the weighted average of $Y_{k, s}(i)$ :

$Y_{s}(i)=\sum_{k=1}^{4} w_{k} \cdot Y_{k, s}(i)$,

where $w_{k}$ is the weight given to the variable $X_{k}$.

\subsubsection{Membership functions}

In general, the design of the membership functions implies a certain degree of subjectivity, and consequently they are usually defined as simple curves. The most common membership functions are triangular, trapezoidal, piecewise linear or Gaussian that reproduce the user's knowledge of the problem (Mendel, 1995). 

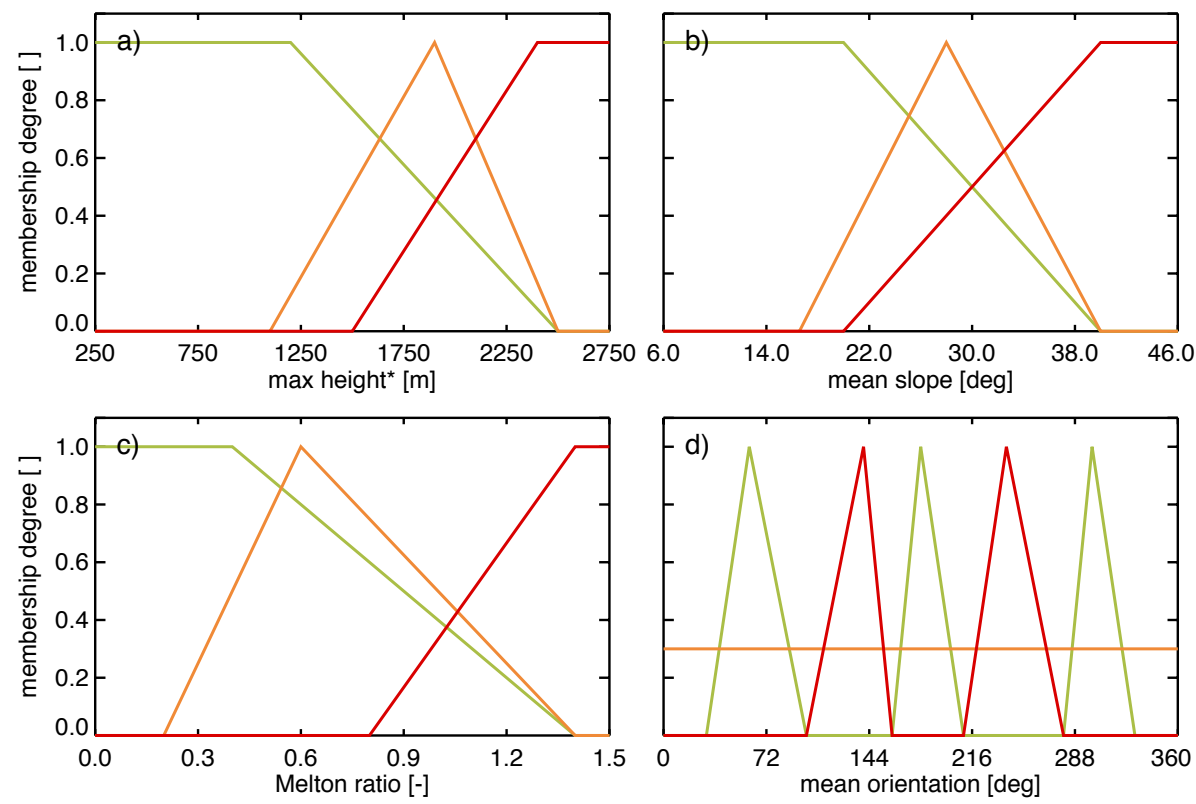

Figure 5. Membership functions used to assess the susceptibility of the subbasins based on (a) $\Delta h_{\max }$, (b) mean slope, (c) Melton ratio and (d) mean orientation of the subbasin. The green, orange and red lines correspond, respectively, to the membership functions for the susceptibility classes "low", "moderate" and "high".

For each of the variables used to assess subbasin susceptibility ( $\Delta h_{\text {max }}, s_{\text {mean }}$, MR and $\theta_{\text {mean }}$ ), we have designed onedimensional membership functions for the three susceptibility classes.

The database presented previously has been used to estimate the proportion of subbasins of type $R=r$ (either reactive or non-reactive) given that $X_{k}=x$ :

$$
f_{r, k}(x)=p\left[R=r \mid X_{k}=x\right] \approx \frac{\#\left(X_{k}=x \cap R=r\right)}{\#\left(X_{k}=x\right)},
$$

where $\#\left(X_{k}=x\right)$ is the number of subbasins in which $X_{k}=$ $x$.

These curves $f_{r, k}(x)$ (see Fig. 15 in Unzeta, 2012) provided valuable information for the construction of the membership functions, whose purpose is to assess the susceptibility of the subbasins where $X_{k}=x$. In this study we have chosen piecewise linear functions whose shape reproduces the information regarding subbasin susceptibility summarized by $f_{r, k}(x)$ (Fig. 5). For instance, Fig. 4b shows that the minimum mean slope of reactive basins in the analysis domain is around $20^{\circ}$ and that the steeper the subbasin, the more reactive. Accordingly, the membership function for the mean slope for the susceptibility class "high" takes a value of 0.0 for angles less than $20^{\circ}$ and increases linearly up to a value of 1.0 over $40^{\circ}$ (Fig. 5b). Reactive subbasins also tend to have high values of MR and $\Delta h_{\max }$ (Figs. $4 \mathrm{a}$ and c, respectively) and, accordingly, the membership functions for the susceptibility class "high" increase with high values of these two variables (Figs. 5a and c). Similarly, the mem-
Table 1. Description of the geomorphological variables used for DF susceptibility assessment and weight estimated with Eq. (4).

\begin{tabular}{llc}
\hline Variable & Description & Weight \\
\hline$h_{\max }[\mathrm{m}]$ & Maximum height of the subbasin & 0.40 \\
$s_{\text {mean }}\left[^{\circ}\right]$ & Mean slope of the subbasin & 0.35 \\
MR $[-]$ & Melton ratio: $\left(h_{\max }-h_{\min }\right) / \sqrt{A}$ & 0.15 \\
$\theta_{\text {mean }}\left[^{\circ}\right]$ & Mean orientation of the subbasin & 0.10 \\
\hline
\end{tabular}

bership function for the susceptibility class "high" for $\theta_{\text {mean }}$ takes high values for two directions that seem more prone to the occurrence of DF. In general, the membership functions for the susceptibility class "low" oppose to those for the susceptibility class "high", and, finally, the membership functions for the susceptibility class "moderate" have been designed as a middle point between the other two categories.

\subsubsection{Adjustment of the weights $w_{k}$}

The weights used to combine the membership degree of the four variables, $Y_{k, s(i)}$ in Eq. (3), have been obtained similarly as proposed by Cho et al. (2006): the weight given to the $k$ th variable is a function of the overlapping area between the pdfs, $h_{r, k}(x)$, of the reactive and non-reactive subbasins, $A_{k}$ :

$$
w_{k}=\frac{1-A_{k}}{\sum_{i=1}^{4} 1-A_{i}} .
$$



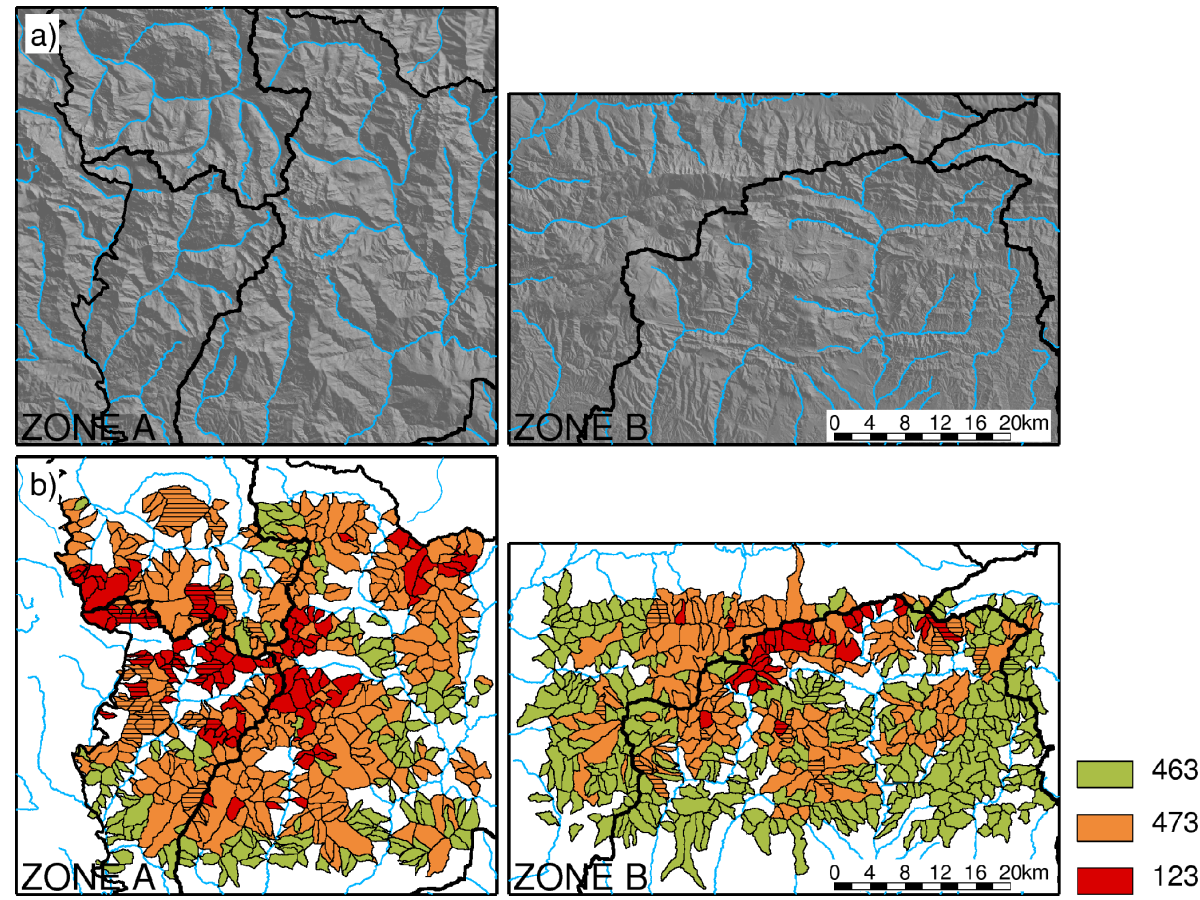

Figure 6. (a) Hillshade map of the analysis domain; (b) DF susceptibility classification based on the highest membership degree in each subbasin (green, orange and red indicate subbasins with susceptibility classified as "low", "moderate" and "high"). Reactive subbasins are filled with a horizontal line pattern. The legend on the right indicates the number of subbasins corresponding to each susceptibility class.

With this method, similar weights have been obtained for $\Delta h_{\text {max }}$ and $s_{\text {mean }}(0.40$ and 0.35 , respectively; right column of Table 1) and clearly smaller weights for MR and $\theta_{\text {mean }}$.

\subsubsection{Susceptibility classification}

The susceptibility classifier produces three maps with the membership degree of each subbasin to the three susceptibility classes ("low", "moderate" and "high"). Since the assessment of subbasin susceptibility is based on static geomorphological variables, these maps are used as static information.

Figure 6 shows the susceptibility map obtained from the class with the highest membership degree in each subbasin $i$ :

$s(i)=\arg \max \left\{Y_{s=\text { low }}(i), Y_{s=\text { moderate }}(i), Y_{s=\text { high }}(i)\right\}$.

Beyond what has been explained about the design of the membership functions in Sect. 3.1.1, the susceptibility map of Fig. 6 has been used in the fine adjustment of the membership functions, focusing on matching the reactive subbasins with those where the susceptibility class is either "moderate" or "high". The classification results in about $44 \%$ of the subbasins with "low" susceptibility (see Table 2). Among these, traces of DF were identified in only four of them in the database introduced in Sect. 2.1.
Table 2. Classification of DF subbasin susceptibility in the study area.

\begin{tabular}{lccc}
\hline Susceptibility & $\begin{array}{c}\text { Non-reactive } \\
\text { subbasins }\end{array}$ & $\begin{array}{c}\text { Reactive } \\
\text { subbasins }\end{array}$ & Total \\
\hline Low & 459 & 4 & 463 \\
Moderate & 438 & 35 & 473 \\
High & 106 & 17 & 123 \\
\hline
\end{tabular}

\subsection{Magnitude of the rainfall situation}

The second element of the developed technique is the characterization of the rainfall situation in terms of its potential to trigger DFs. We have adopted the results obtained with the physically based model of Papa et al. (2013) as implemented by Bateman et al. (2010). This approach models shallow landslide triggering by rain infiltration. It assesses the stability of a generic element of the basin based on infiniteslope stability analysis (e.g., Taylor, 1948; Iverson, 2000) by comparing the gravitational driving stress and the resisting Coulomb friction. The effect of rainfall infiltration on groundwater pressure head assumes vertical flow (Iverson, 2000), and the effect of the antecedent rain uses the hypothesis of steady-state conditions. Characteristic values of the model parameters (namely the local slope, soil depth, depthaveraged soil unit weight, internal friction angle, soil cohe- 


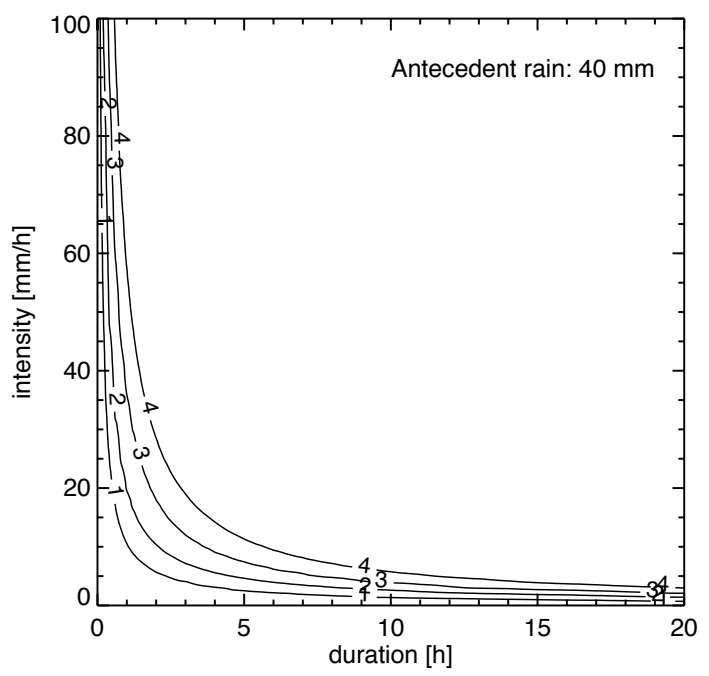

Figure 7. Example of the curves used for diagnosing the percent of subbasin unstable area based on rainfall duration and mean intensity. This case is for an antecedent rain of $40 \mathrm{~mm}$.

sion, maximum characteristic diffusivity near saturation and hydraulic conductivities parallel and normal to the slope direction) have been estimated for the analysis domain (Bateman et al., 2010), and the stability model has been applied for the possible rainfall situations. These have been characterized by the duration of the rainfall event, $D$, mean rainfall intensity, $R$, and antecedent rain, $\mathrm{AR}$, computed over the time for the soil to reach steady-state conditions.

In our study, radar rainfall estimates have been used to obtain the values of AR, $D$ and $R$ to sample the curves obtained with the model of Papa et al. (2013) in each subbasin at each time step. The result of the stability model is the unstable area within each subbasin (expressed as \%, Fig. 7), which is the variable used to classify the rainfall situation as "weak", "moderate" and "severe" based on fuzzy logic, similarly as done above for the classification of subbasin susceptibility.

It has to be noted that the model of Papa et al. (2013) is valid for rainfall-triggered landslides that evolve into DFs and, therefore, it does not appropriately characterize other DF initiation mechanisms (such as progressive entrainment of sediment into a water flow).

\subsubsection{Variables and membership functions}

The subbasin unstable area computed with the model of Papa et al. (2013) is the variable used to characterize the magnitude of the rainfall situation in terms of its potential to produce DFs.

The membership functions used for this variable are also piecewise linear (see Fig. 8). The definition of these functions is based on the criteria proposed by Medina and Zappa (2011). Conceptually, we interpret the crossover point between the membership functions for "weak" and "severe" rainfall events (corresponding to an unstable area of $2.5 \%$

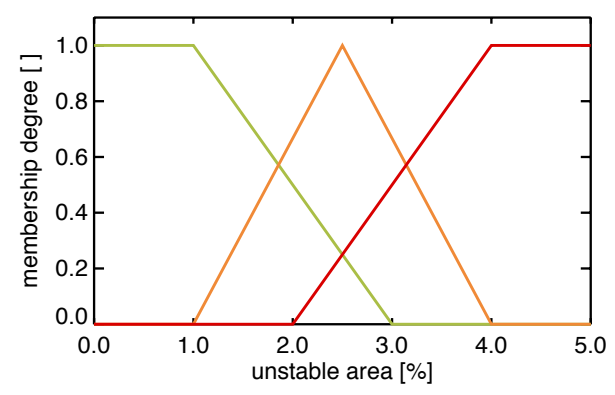

Figure 8. Membership function for the unstable area used in the assessment of the magnitude of the rainfall event. The green, orange and red lines correspond, respectively, to the membership functions for the classes "weak", "moderate" and "severe" rainfall situation.

in Fig. 8) as the critical intensity-duration threshold for landslide or DF triggering, proposed by many authors (e.g., Guzzetti et al., 2008; Brunetti et al., 2010). However, further analyses beyond the scope of this paper would be required to verify that this is satisfied by the results obtained with the model of Papa et al. (2013) in the analysis domain.

\subsubsection{Rainfall scenario classification}

Similarly as for the susceptibility classifier, this classifier produces three maps with the membership degree $Y_{r}$ of each subbasin to the three classes ("weak", "moderate" and "severe" rainfall). Figure $9 \mathrm{~b}$ shows the implementation of the classifier on 23 July 2011 at 00:30 UTC and the class with the highest membership degree for each subbasin.

\subsubsection{Implementation aspects}

For the implementation of this module, decisions have been made regarding the rainfall product and the definition of rainfall event. We have chosen to use $30 \mathrm{~min}$ accumulations aggregated over the area of each subbasin. This seems to be a good compromise to capture the rapid evolution of local convective phenomena affecting small areas at a reasonable computational cost. On the other hand, the definition of rainfall event plays an important role in the performance of the slope stability model of Papa et al. (2013), as the antecedent rain is recalculated when a new event starts. Here, we have assumed that a rainfall event ends at a given subbasin when it does not rain for more than $6 \mathrm{~h}$, and a new event begins when it starts raining again in the same subbasin.

Finally, it is worth pointing out that each subbasin is treated independently. Consequently, in different subbasins rainfall events start and end at different times, with different conditions of antecedent rainfall, and the computation of the unstable area uses different rainfall intensities and event durations. 
a) Rain rate
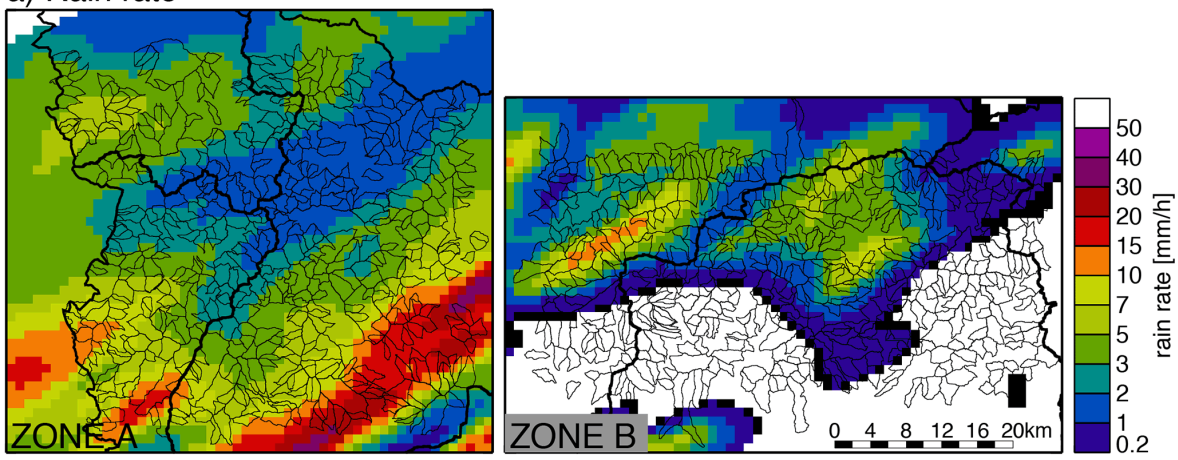

b) Rainfall scenario
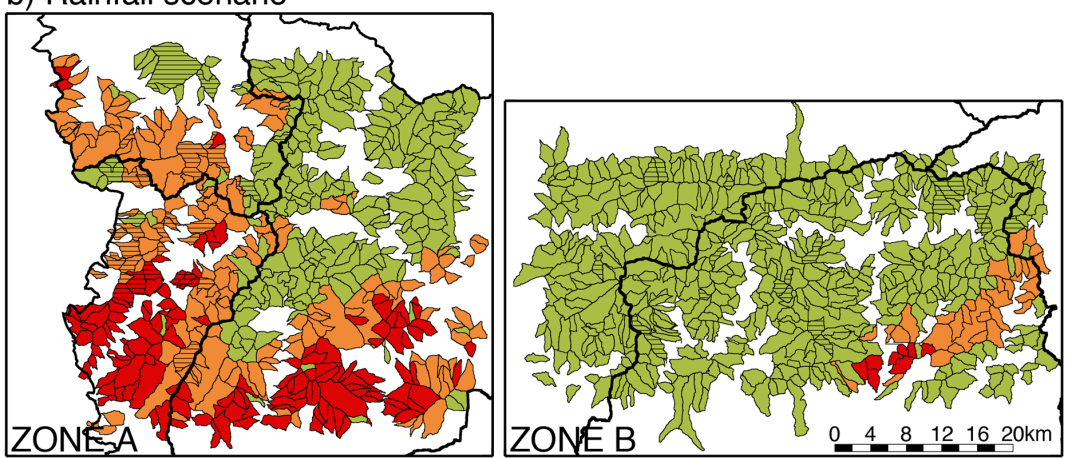

c) Warning level
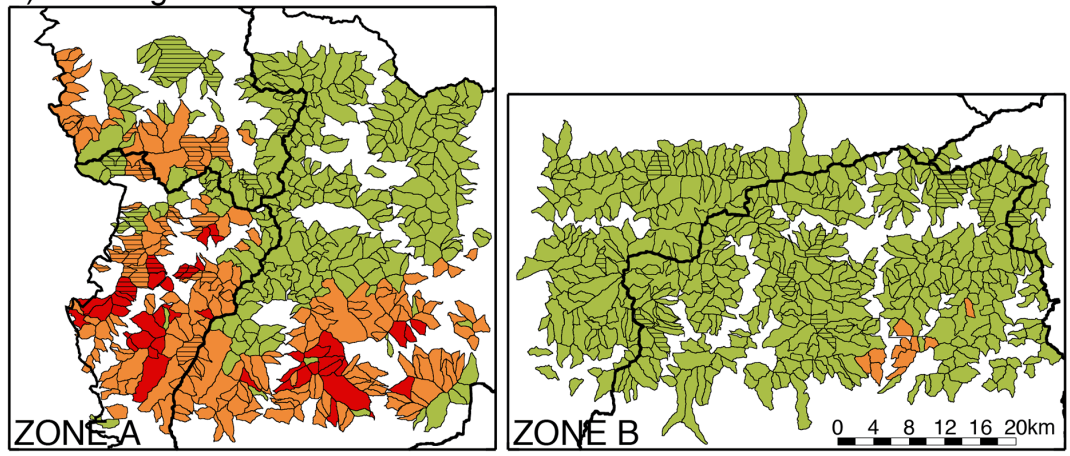

Figure 9. Example of the implementation of the developed technique over the analysis domain on 23 July 2010 at 01:30 UTC: (a) 30 min rainfall intensity estimated from radar observations; (b) magnitude of the rainfall situation estimated in each subbasin (green, orange and red correspond to the classes "weak", "moderate" and "severe" rainfall); (c) warning level obtained in each subbasin (green, orange and red correspond to the warning level classes "low", "medium" and "high").

\subsection{DF warning level}

The DF warning level, $W$, is finally obtained by combining the fuzzy classifications for (i) subbasin susceptibility, $S$, and (ii) the magnitude of the rainfall situation, $R$, through a fuzzy rule (e.g., Bardossy and Duckstein, 1995). The rule is based on a logic table that describes the expected behavior of the system to issue a classification of the DF warning level at a given subbasin as "low", "moderate" or "high". In our case, the implemented rule is summarized with the matrix shown in Fig. 10, which can also be written as

$$
\text { if }\left\{\begin{array}{c}
{\left[\left(R \in R_{1}\right) \cap\left(S \in S_{1}\right)\right]} \\
\cup\left[\left(R \in R_{1}\right) \cap\left(S \in S_{2}\right)\right] \\
\cup\left[\left(R \in R_{1}\right) \cap\left(S \in S_{3}\right)\right] \\
\cup\left[\left(R \in R_{2}\right) \cap\left(S \in S_{1}\right)\right]
\end{array}\right\} \Rightarrow W \in W_{1}
$$

For example, in subbasins with "low" susceptibility $(S \in$ $\left.S_{1}\right)$, the DF warning level is "low" $\left(W \in W_{1}\right)$ unless the rain- 
fall situation is "severe" $\left(R \in R_{3}\right)$; similarly, the expected DF warning level is classified as "high" $\left(W \in W_{3}\right)$ if the rainfall situation is "severe" $\left(R \in R_{3}\right)$, except in subbasins with "low" susceptibility $\left(S \in S_{1}\right)$. However, the expressions $Z \in Z_{l}$ ( $Z$ being either $R, S$ or $W$ ) are quantified by means of the fuzzy membership degree, and the operators intersection and union $(\cap$ and $\cup$ ) are also intersection and union fuzzy operators (e.g., Bardossy and Duckstein, 1995). After testing several alternatives (for full details, see Unzeta, 2012), we have used the algebraic product and the algebraic sum, respectively (e.g., Bardossy and Duckstein, 1995). That is,

$$
\begin{aligned}
& \left(R \in R_{j}\right) \cap\left(S \in S_{k}\right)=Y_{r_{j}} \cdot Y_{S_{k}}, \\
& \left(R \in R_{j}\right) \cup\left(S \in S_{k}\right)=Y_{r_{j}}+Y_{s_{k}}-Y_{r_{j}} \cdot Y_{s_{k}} .
\end{aligned}
$$

Evaluating the three expressions of Eq. (6) we obtain the validity $v_{l}$ of each of the expressions $W \in W_{l}$ (for $l=1 / 3$ ); finally, the warning level $l_{\mathrm{c}}(i)$ assigned to subbasin $i$ is the most valid one:

$l_{\mathrm{c}}(i)=\arg \max \left(v_{1}, v_{2}, v_{3}\right)$.

Figure $9 \mathrm{c}$ shows an example of the DF warning level obtained in the analysis domain on 23 July 2010 at 00:30 UTC.

\section{Results}

The developed classifier has been implemented in two subdomains in the eastern Pyrenees in the period 1 May-31 October 2010. The presentation of the results focuses first on an overall analysis of the warning level obtained with the developed technique along the analyzed period; in the second part, its performance is evaluated for specific subbasins during selected heavy rain events.

\subsection{DF warning in the period May-October 2010}

Figure 11 shows the number of days the warning level was "moderate" and "high" in the subbasins of the analysis domain during the analyzed period. The DF warning level was "moderate" at least once in most of the subbasins (in 844 of the 1059 analyzed subbasins), and in 174 subbasins the warning level was "high" at least once. The maximum number of days (10) with warning level not "low" is in three subbasins in the southern part of zone A and in one subbasin in the eastern part of zone B. In most of the subbasins the warning level was "high" for 1 or 2 days (except in two subbasins of zone A, where the warning level was "high" for up to 5 days). As expected, the areas with more frequent warnings coincide with the most susceptible subbasins that were affected by large rainfall amounts (for example, in the southern-central portion of zone A, where rainfall estimates exceeded $1000 \mathrm{~mm}$; Figs. 2 and 6). Similarly, the scarcity of warnings in the southwest of zone B coincides with the area

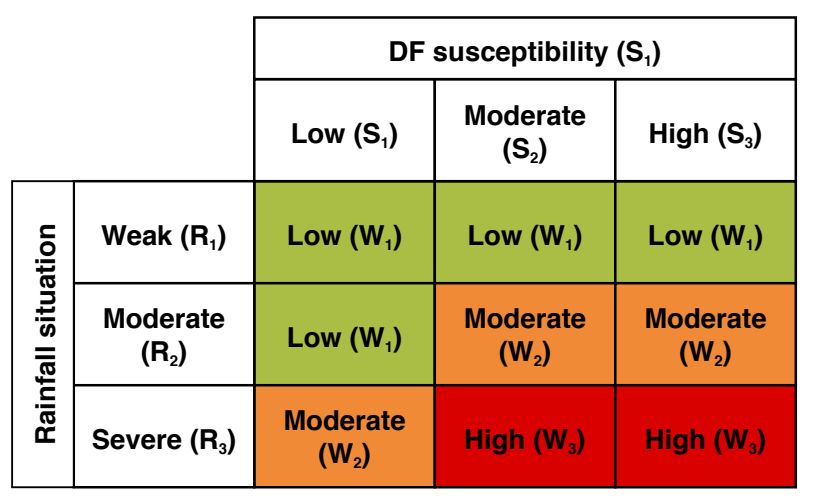

Figure 10. Rule used to derive the DF warning level from the combination of subbasin DF susceptibility and the magnitude of the rainfall situation.

with low rain amounts in subbasins with low DF susceptibility.

The results obtained for the analysis period show that in some basins the warning level was "high" for a significant number of days and, consequently, we would expect some DF occurrence. However, validation of these results is difficult, because no systematic DF records are available in the area of study for the analysis period. Furthermore, in some of the cases there might be DF occurrence but with no impact on people or goods. Thus, very little information remains for validation of our results.

The only alternative for quantitative analysis of the results has been focusing on a few subbasins where DF records exist. Next section focuses on the results obtained in a subbasin where DFs were systematically monitored during the analysis period.

\subsection{Case studies}

This section analyzes the performance of the developed technique in the catchment of the Rebaixader torrent (a "moderately" susceptible subbasin located in zone A near the village of Senet, Lleida, Spain; Fig. 1) from May to October 2010. The torrent runs over a glacial moraine and bedrock outcrops, and the source for debris flows is a steep scarp in the moraine. The exact DF initiation mechanisms are not resolved but may be a combination of small-scale slope failures and superficial and channel erosion with progressive entrainment of sediment into the flow. DF occurrence has been systematically monitored with a network of wired and wireless sensors since 2009 (Hürlimann et al., 2014), which provides a unique reference for quantitative evaluation of DF occurrence and hazard assessment in the subbasin. The system includes five geophones measuring ground vibration and an ultrasonic level gauge from which DF occurrence is determined (Abancó et al., 2014).

Rainfall observations in the catchment are recorded with a rain gauge collocated with the geophones (hereafter referred 
a) Days with moderate warning level

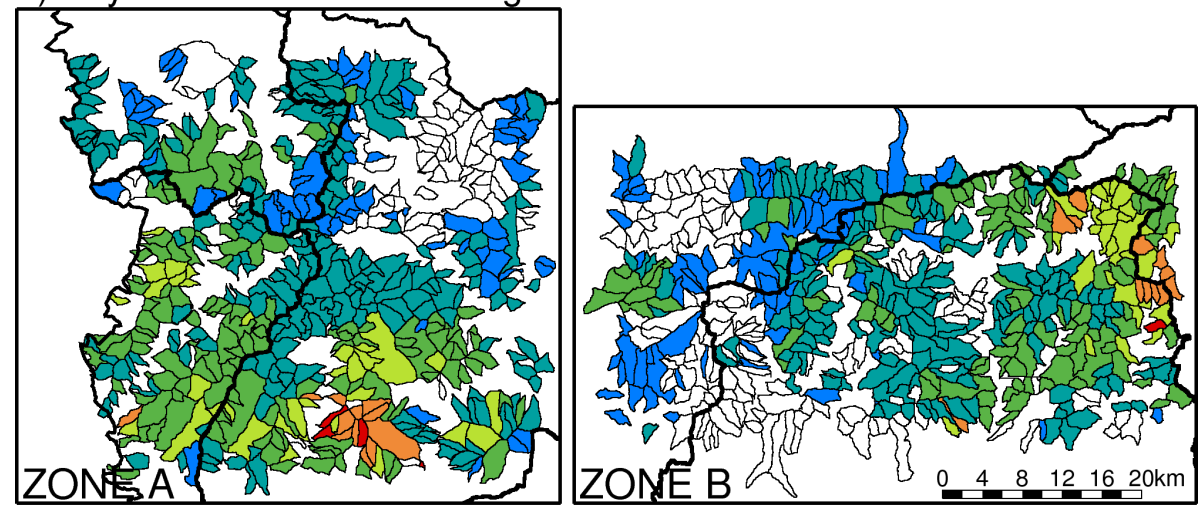

b) Days with high warning level

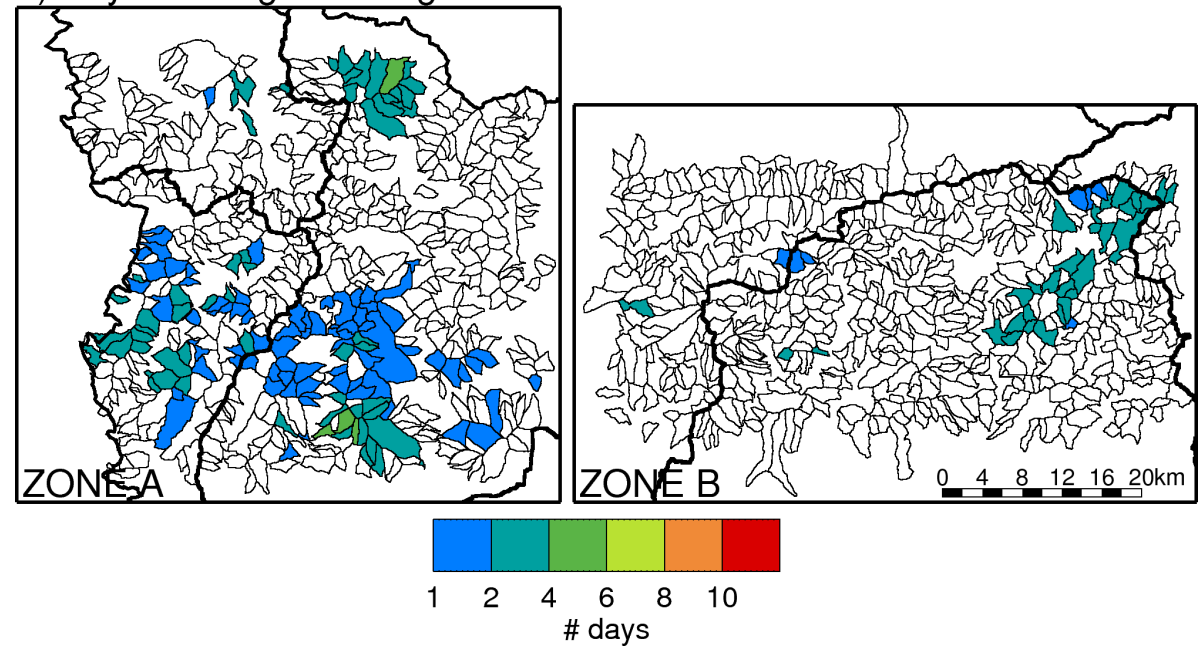

Figure 11. Number of days for which the warning level in the period 1 May to 31 October 2010 was (a) "moderate" and (b) "high".

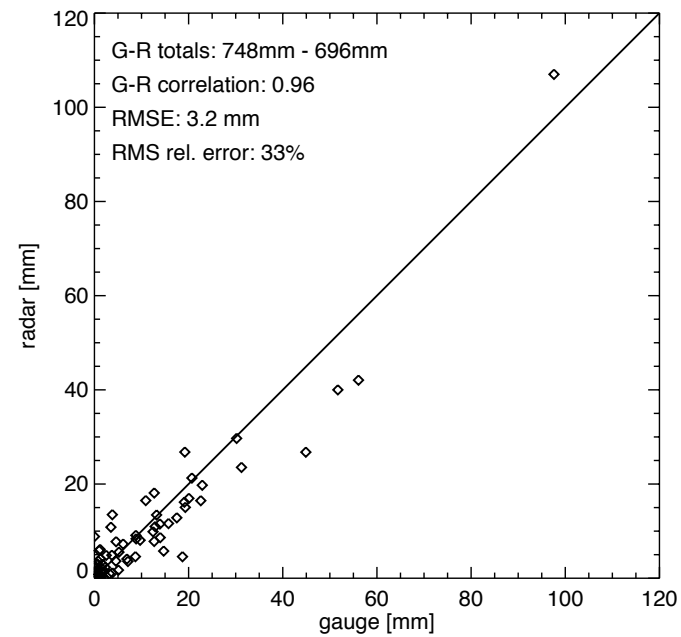

Figure 12. Scatterplot of $24 \mathrm{~h}$ accumulations recorded with the Senet rain gauge (located in the Rebaixader catchment) and the Creu del Vent radar in the period from 1 May to 31 October 2010. to as the Senet rain gauge). A second rain gauge exists $6 \mathrm{~km}$ from the catchment, in the nearby village of Barruera. During the studied period, the Senet and the Barruera rain gauges accumulated 748 and $699 \mathrm{~mm}$, respectively, whereas radar estimated 696 and $668 \mathrm{~mm}$. The scatterplots of radar vs. rain gauge daily accumulations show remarkable agreement (see Fig. 12).

During the analysis period the monitoring system detected three significant cases: one debris flow and two hyperconcentrated flows (also called debris floods); the latter can also be hazardous for persons and infrastructure (Hungr et al., 2014). Debris flows show peak discharges that are much larger than those of debris floods and the presence of the bouldery front (Hungr et al., 2001). The presence of these characteristics in geophone and level measurements have been used to classify the different events (see Abancó et al., 2014; Hürlimann et al., 2014, for further details).

This section analyzes the results obtained in the catchment for five illustrative rainfall events, including the four cases for which the obtained warning level was either "moderate" 

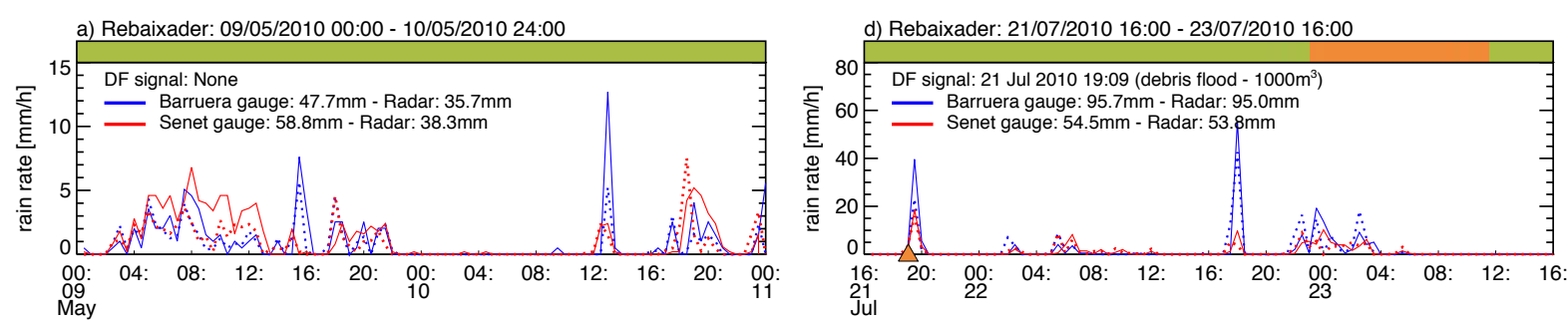

b) Rebaixader: 08/06/2010 16:00 - 10/06/2010 15:00

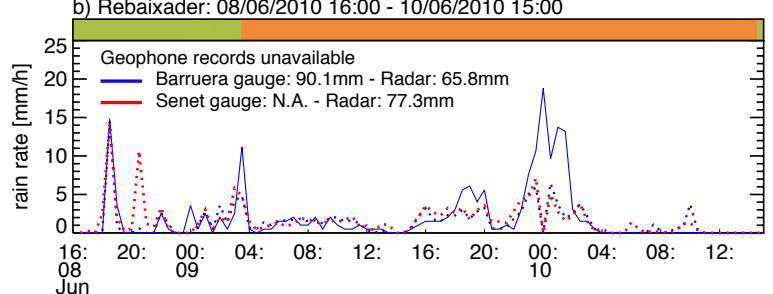

e) Rebaixader: 09/10/2010 16:00 - 11/10/2010 18:00

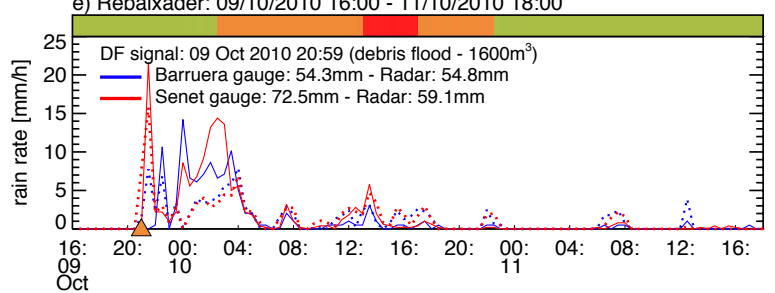

c) Rebaixader: 11/07/2010 06:00 - 11/07/2010 24:00

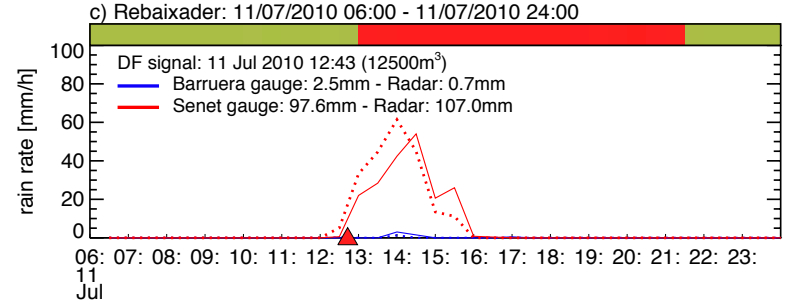

Figure 13. Time series of $30 \mathrm{~min}$ rain rate observed with the Barruera and Senet rain gauges (blue and red solid lines, respectively) during five rainfall events in the Rebaixader catchment. The two dashed lines correspond to the radar QPE collocated with the two rain gauges. The top color bar shows the time series of the warning level obtained in the Rebaixader subbasin: green, orange and red correspond, respectively, to DF warning level "low", "moderate" and "high". The orange and red triangles on the $x$ axis indicate, respectively, the beginning of debris flood and debris flood events detected from geophone records (the text indicates the exact timing and the estimated sediment volume).

Table 3. Summary of the results obtained in the Rebaixader subbasin for the events presented in Sect. 4.2; "DFlow" and "DFlood" stand for "debris flow" and "debris flood", respectively.

\begin{tabular}{lccc}
\hline Event & $\begin{array}{c}\text { Warning } \\
\text { level }\end{array}$ & $\begin{array}{c}\text { Observed } \\
\text { response }\end{array}$ & $\begin{array}{c}\text { Sediment } \\
\text { volume }\left[\mathrm{m}^{3}\right]\end{array}$ \\
\hline 9-10 May 2010 & Low & None & - \\
8-10 Jun 2010 & Moderate & N/A & N/A \\
11 Jul 2010 & High & DFlow & 12500 \\
21-23 Jul 2010 & Moderate & DFlood & 1000 \\
9-11 Oct 2010 & High & DFlood & 1600 \\
\hline
\end{tabular}

or "high" during the analysis period (see Table 3 for a summary).

\subsubsection{Case 1: 9-10 May 2010}

This event produced a large part of the rainfall accumulated over the catchment in the month of May. Figure 13a shows that radar QPE underestimated the rainfall measured with rain gauges (especially in the early part of the event). Since rainfall intensities along the event were not particularly high, the DF warning level did not change from "low" throughout the event (unlike in other areas of the analysis domain). This is in agreement with geophone observations, which show no DF signal in the catchment. Consequently, this case can be considered an example of correct negative assessment (i.e., no warning was issued and no DF was detected).

\subsubsection{Case 2: 7-10 June 2010}

Although the comparison between radar and rain gauge observations in Barruera (Fig. 13b) seems to indicate that radar underestimated the total accumulated rainfall over the Rebaixader catchment, the warning level turned to "moderate" on 9 June 2010 at 03:00 UTC lasting until the end of the event on 10 June 2010 at 14:30 UTC. Unfortunately, the geophone records were not available for this event; however, given the high intensities and the total accumulated rainfall it seems plausible that some hyperconcentrated flow or even a small debris flow could have occurred in the catchment.

\subsubsection{Case 3: 11 July 2010}

During this event a local convective rainstorm affected the basin for around $4 \mathrm{~h}$ (see Fig. 13c) and produced the second largest DF in the period 2009-2013 (Hürlimann et al., 2014). Both radar and rain gauge observations show similar evolu- 
tion of the very high rainfall intensities and registered total accumulations of 107.0 and $97.6 \mathrm{~mm}$, respectively.

The DF warning level changed to "high" on 11 July 2010 at 12:30 UTC, lasting until the end of the event. This coincides almost exactly with the geophone signal, which started at 12:43 UTC.

\subsubsection{Case 4: 21-23 July 2010}

During this event the obtained DF warning level was "moderate" or "high" in a large number of subbasins due to numerous convective cells developing and crossing the entire analysis domain (a characteristic rainfall intensity map for this event is shown in Fig. 9a).

A short period of intense rainfall affected the Rebaixader catchment at the beginning of the event (21 July 2010, 18:00-21:00 UTC). However, Fig. 13d shows that this was not enough to produce a change of the DF warning level until 22 July 2011 at 22:30 UTC. Contrarily, geophone records show some reaction in the basin starting on 21 July 2010 at 19:05 UTC. This signal was attributed to a less dense hyperconcentrated flow (or debris flood). Consequently, the timing of the beginning of the event was clearly missed.

This same event probably produced DFs in many other subbasins. In particular, M. Hürlimann (personal communication, 2012) reported DFs in the Erill torrent, a catchment with frequent DF activity, and in the Port Ainé catchment (subbasins 2 and 3 in Fig. 1). These are two "moderately" susceptible subbasins (as determined with the classification of Sect. 3.1), and in both cases the DFs occurred during the night of 22-23 July 2010 with the exact timing unknown. The event in the Erill torrent was a relatively large DF with a volume of about $1300 \mathrm{~m}^{3}$ (Raïmat et al., 2013).

In the Erill subbasin, the DF warning level changed to "moderate" on 22 July 2010 at 17:00 UTC (Fig. 14a), coinciding with a very intense rainfall period in which more than $20 \mathrm{~mm}$ were accumulated in the basin in $30 \mathrm{~min}$, and became "high" at 23:00 UTC and lasted until the end of the event, in the morning of 23 July 2010. In the Port Ainé catchment the warning level turned "moderate" after 22 July 2010 at 23:30 UTC and lasted until the end of the event (Fig. 14b).

\subsubsection{Case 5: 9-10 October 2010}

In the Rebaixader subbasin, the signal of the geophones was associated with a debris flood starting on 9 October 2010 at 20:59 UTC, coinciding with heavy rainfall intensities over the basin (Fig. 13e). The estimated DF warning level turned "moderate" on 10 October 2010 at 02:00 UTC, increased to "high" between 12:30 and 16:30 and stayed as "moderate" until the end of the event. The behavior of the technique at the beginning of this event is similar to that for the event of 21-23 July 2010 in the Rebaixader subbasin: radar QPE underestimated the heavy rainfall intensities recorded with rain gauges at the beginning of the event and did not produce the

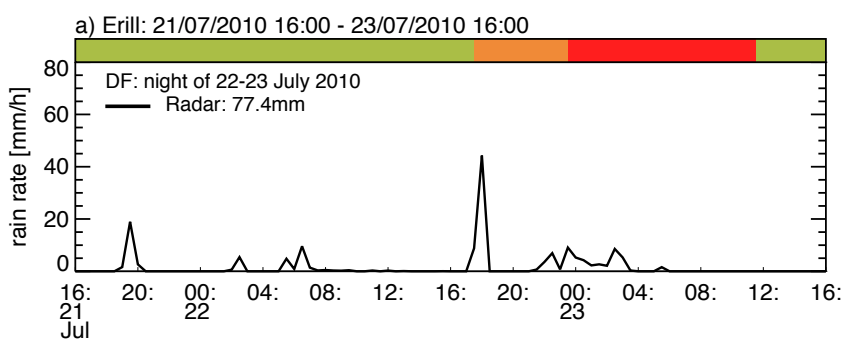

b) Portaine: 21/07/2010 16:00 - 23/07/2010 16:00

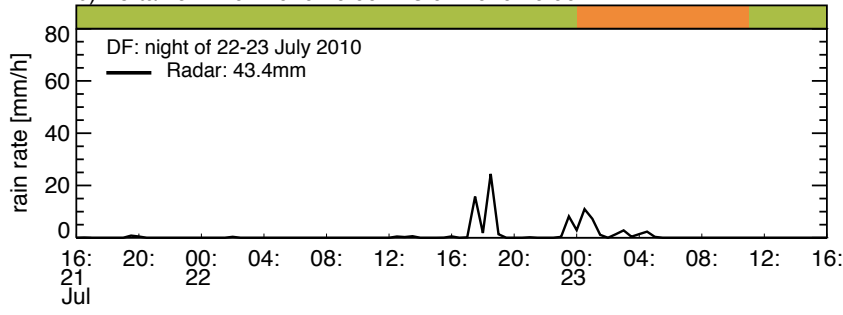

Figure 14. Same as Fig. 13 but for the event of 21-23 July 2010 in the Erill torrent (a) and in the Port Ainé subbasin (b). The solid black lines show the estimated rain rate in the subbasin.

values of unstable area required for "moderate" DF warning until $5.5 \mathrm{~h}$ after the first signal detected with the geophones.

\section{Conclusions and discussion}

A technique for issuing DF warnings using radar rainfall maps has been developed and implemented into two subdomains in the central-eastern Pyrenees. We have opted for a simple and flexible fuzzy logic technique that classifies the DF warning level into "low", "moderate" and "high" based on two ingredients: (i) the DF susceptibility of the subbasins and (ii) the magnitude of the rainfall situation.

The performance of the technique has been demonstrated for the warm season of 2010. For this period, the technique estimated "moderate" and "high" warnings in many of the subbasins of the analysis domain, especially related to a few intense rainfall events. This analysis also confirmed the expected correspondence between the areas with a large number of days with "moderate" and "high" DF warnings and the areas with susceptible subbasins affected by large amounts of precipitation.

The lack of extensive reports of DF occurrence in the area makes the systematic verification of the DF warning level estimated with the technique over the entire domain impossible. Geophone records of a monitoring system were available in a "moderately" susceptible subbasin, which allowed studying the performance of the developed technique during the DF season of 2010. In this subbasin, the technique did not produce any false alarm, showing the behavior of the technique in events with moderate rainfall intensities for which no DF activity was reported and issued significant warnings during all the reported cases. The results 
are very positive in situations of DFs: this is the case of the event of 11 July 2010 in the Rebaixader subbasin (the timing of the delivered DF hazard warning matches geophone records), and the case occurred in the Erill catchment during the night of 22-23 July 2010, for which the warning level was "high". The exact timing of the latter event is unknown, but the obtained warning level seems consistent with the time series of rainfall in the basin. Finally, for all the debris flood cases in the Rebaixader catchment, the warning level turned into "moderate" with some delay with respect to geophone records. This is due to the fact that the intensity-duration curves of Papa et al. (2013) sampled with radar rainfall estimates (which underestimated the highest intensities observed with an in situ rain gauge) resulted in insufficient unstable area to classify the rainfall situation as "moderate" or "severe" at the beginning of the event. The fact that DFs in the Rebaixader subbasin are probably initiated by a combination of superficial erosion and slope instability (the mechanism considered by the model of Papa et al., 2013) can also in part explain the faster reaction of the basin.

The high space-time resolution of radar QPE products fits the requirements of DF early warning systems: they provide at least one rainfall measurement in each subbasin, which cannot be guaranteed with operational rain gauge networks at regional scale. However, it is fundamental to guarantee the quality of QPE products (see also Wilson, 2004). For instance, positive (or negative) biases in radar QPE products would result in systematic DF false alarms (or missed DF events). Alternatively, radar rain gauge blending products could be used (e.g., Velasco-Forero et al., 2009; Schiemann et al., 2011). These benefit from the radar depiction of the variability of the rainfall field (fundamental in convective situations), while imposing the available rain gauge observations.

In this work, we have used two data sets available in the analysis domain.

- The geomorphological variables derived by Chevalier et al. (2013) to characterize DF susceptibility: this approach has the advantage of using information that is frequently available in many areas (from the analysis of a DEM) but neglects information relative to the soil depth or the lithology that are relevant predictors to characterize DF susceptibility.

- The results of the model of Papa et al. (2013) obtained by Bateman et al. (2010) to characterize the magnitude of the rainfall situation: this model is rather complex and requires soil information that could also be valuable to improve the characterization of DF susceptibility.

One of the advantages of the developed technique is that its modules can be replaced easily. In this sense, other methods for assessing DF susceptibility (He et al., 2003; Marchi and Dalla Fontana, 2005; Ayalew et al., 2004; Lee, 2007) could be implemented. The integration of an alternative technique would require the expert adjustment of the membership functions for the new variables. Similarly, other techniques could be implemented for assessing the magnitude of the rainfall event. In this sense, an interesting alternative could be the use of intensity-duration curves, available in several locations (e.g., Wieczorek and Guzzetti, 2000; Corominas et al., 2002; Guzzetti et al., 2008; Brunetti et al., 2010; Portilla et al., 2010). In particular, the definition of the membership functions would be facilitated by those methods that provide information about the magnitude of the event or the probability of DF occurrence beyond the yes/no output of threshold methods (e.g., Brunetti et al., 2010).

Finally, in the context of a DF EWS, it would be necessary to implement the developed methodology for DF warning with high-resolution rainfall forecasts to extend the lead time to take effective action. The lead times of NWP models (typically, beyond 1 day) enable earlier preparedness and allow preparing effective emergency and response plans. However, DFs are sometimes triggered by small-scale rainfall systems that are not well resolved by most available NWP systems. At these scales, radar-based nowcasting techniques (e.g., Berenguer et al., 2011, 2012, and references therein) have shown certain skill in forecasting the evolution of the rainfall field for a few hours. They are a good complement to NWP to monitor the ongoing rainfall situation in the context of a DF EWS.

Acknowledgements. We acknowledge the Catalan Weather Service (SMC) for providing the radar data and rain gauge observations and the Catalan Water Agency for providing rain gauge observations. We thank the contribution of Clara Unzeta, who worked on a preliminary version of this study in the context of her civil engineering undergraduate project. We are also indebted with V. Medina, G. Chevalier, F. Bregoli and A. Bateman (Sediment Transport Research Group, Technical University of Catalonia) for providing the data used in the susceptibility analysis and the intensity-duration curves obtained with the slope stability model. This work has been done in the framework of the EC project IMPRINTS (FP7-ENV-2008-1 IMPRINTS 226555) and the Spanish project ProFEWS (CGL2010-15892). The debris-flow monitoring is funded by the Spanish project DEBRISTART (CGL2011-23300). The first author is supported with a grant from the Ramón y Cajal Program of the Spanish Ministry of Economy and Competitiveness (RYC2010-06521).

Edited by: A. Günther

Reviewed by: J.-P. Malet and one anonymous referee 


\section{References}

Abancó, C., Hürlimann, M., and Moya, J.: Analysis of the ground vibration generated by debris flows and other torrential processes at the Rebaixader monitoring site (Central Pyrenees, Spain), Nat. Hazards Earth Syst. Sci., 14, 929-943, doi:10.5194/nhess-14929-2014, 2014.

Aleotti, P.: A warning system for rainfall-induced shallow failures, Eng. Geol., 73, 247-265, 2004.

Alfieri, L., Salamon, P., Pappenberger, F., Wetterhall, F., and Thielen, J.: Operational early warning systems for water-related hazards in Europe, Environ. Sci. Policy, 21, 35-49, 2012.

Ayalew, L., Yamagishi, H., and Ugawa, N.: Landslide susceptibility mapping using GIS-based weighted linear combination, the case in Tsugawa area of Agano River, Niigata Prefecture, Japan, Landslides, 1, 73-81, 2004.

Bardossy, A. and Duckstein, L.: Fuzzy Rule-Based Modeling with Applications to Geophysical, Biological, and Engineering Systems, CRC Press, Boca Raton, Florida, USA, 1995.

Bateman, A., Papa, M. N., Hürlimann, M., Bregoli, F., Chevalier, G., Ciervo, F., and Medina, V.: Simulation methodology to build the rule-based probabilistic forecasting system, Report, FP7 project IMPRINTS, 2010.

Baum, R. L. and Godt, J. W.: Early warning of rainfall-induced shallow landslides and debris flows in the USA, Landslides, 7, 259272, 2010.

Ben David-Novak, H., Morin, E., and Enzel, Y.: Modern extreme storms and the rainfall thresholds for initiating debris flows on the hyperarid western escarpment of the Dead Sea, Israel, Geol. Soc. Am. Bull., 116, 718-728, 2004.

Berenguer, M., Sempere-Torres, D., Corral, C., and SanchezDiezma, R.: A fuzzy logic technique for identifying nonprecipitating echoes in radar scans, J. Atmos. Ocean. Technol., 23, 1157-1180, 2006.

Berenguer, M., Sempere-Torres, D., and Pegram, G. G. S.: SBMcast - An ensemble nowcasting technique to assess the uncertainty in rainfall forecasts by Lagrangian extrapolation, J. Hydrol., 404, 226-240, 2011.

Berenguer, M., Surcel, M., Zawadzki, I., Xue, M., and Kong, F.: The Diurnal Cycle of Precipitation from Continental Radar Mosaics and Numerical Weather Prediction Models. Part II: Intercomparison among Numerical Models and with Nowcasting, Mon. Weather Rev., 140, 2689-2705, 2012.

Bovis, M. J. and Jakob, M.: The role of debris supply conditions in predicting debris flow activity, Earth Surf. Proc. Land., 24, 10391054, 1999.

Brunetti, M. T., Peruccacci, S., Rossi, M., Luciani, S., Valigi, D., and Guzzetti, F.: Rainfall thresholds for the possible occurrence of landslides in Italy, Nat. Hazards Earth Syst. Sci., 10, 447-458, doi:10.5194/nhess-10-447-2010, 2010.

Chen, H. and Lee, C.: Geohazards of slope mass movement and its prevention in Hong Kong, Eng. Geol., 76, 3-25, 2004.

Chevalier, G.: Assessing debris-flow hazard focusing on statistical morpho-fluvial susceptibiity models and magnitude-frequency relationships, $\mathrm{PhD}$ Thesis, Civil Engineering School, Technical University of Catalonia, Barcelona, Spain, available at: http://tdx.cat/bitstream/handle/10803/128804/TGGC1de1.pdf? sequence=1 (last access: 11 March 2015), 2013.

Chevalier, G. G., Medina, V., Hürlimann, M., and Bateman, A.: Debris-flow susceptibility analysis using fluvio-morphological parameters and data mining: application to the Central-Eastern Pyrenees, Nat. Hazards, 67, 213-238, 2013.

Cho, Y. H., Lee, G., Kim, K. E., and Zawadzki, I.: Identification and removal of ground echoes and anomalous propagation using the characteristics of radar echoes, J. Atmos. Ocean. Technol., 23, 1206-1222, 2006.

Corominas, J. and Santacana, N.: Stability analysis of the Vallcebre translational slide, Eastern Pyrenees (Spain) by means of a GIS, Nat. Hazards, 30, 473-485, 2003.

Corominas, J., Moya, J., and Hürlimann, M.: Landslide rainfall triggers in the Spanish eastern Pyrenees, in: Mediterranean Storms, Proceedings of the 4th Plinius Conference 2002, European Geophysical Society, Mallorca, Spain, 2-4 October, 2002.

Corominas, J., Copons, R., Vilaplana, J. M., Altimir, J., and Amigó, J.: Integrated Landslide Susceptibility Analysis and Hazard Assessment in the Principality of Andorra, Nat. Hazards, 30, 421435, 2003.

Corral, C., Velasco, D., Forcadell, D., and Sempere-Torres, D.: Advances in radar-based flood warning systems. The EHIMI system and the experience in the Besòs flash-flood pilot basin, Taylor \& Francis, London, UK, 1295-1303, 2009.

Delrieu, G., Creutin, J. D., and Andrieu, H.: Simulation of Radar Mountain Returns Using a Digitized Terrain Model, J. Atmos. Ocean. Technol., 12, 1038-1049, 1995.

EC: Directive 2007/60/EC on the assessment and management of flood risks, Tech. rep., European Commission, Strasbourgh, France, 2007.

Egashira, S.: Review of research related to sediment disaster mitigation, J. Disaster Res., 2, 33-40, 2007.

Franco, M., Sánchez-Diezma, R., and Sempere-Torres, D.: Improvements in weather radar rain rate estimates using a method for identifying the vertical profile of reflectivity from volume radar scans, Meteorologische Zeitschrift, 15, 521-536, 2006.

Franco, M., Sánchez-Diezma, R., Sempere-Torres, D., and Zawadzki, I.: Improving radar precipitation estimates by applying a VPR correction method based on separating precipitation types, in: 5th European Conference on Radar in Meteorology and Hydrology, Helsinki, Finland, 30 June-4 July 2008, 14-16, 2008.

Guzzetti, F., Peruccacci, S., Rossi, M., and Stark, C. P.: The rainfall intensity-duration control of shallow landslides and debris flows: an update, Landslides, 5, 3-17, 2008.

He, Y. P., Xie, H., Cui, P., Wei, F. Q., Zhong, D. L., and Gardner, J. S.: GIS-based hazard mapping and zonation of debris flows in Xiaojiang Basin, southwestern China, Environ. Geol., 45, 286293, 2003.

Hong, Y. and Adler, R. F.: Towards an early-warning system for global landslides triggered by rainfall and earthquake, Int. J. Remote Sens., 28, 3713-3719, 2007.

Hungr, O., Evans, S. G., Bovis, M. J., and Hutchinson, J. N.: A review of the classification of landslides of the flow type, Environ. Eng. Geosci., 7, 221-238, 2001.

Hungr, O., Leroueil, S., and Picarelli, L.: The Varnes classification of landslide types, an update, Landslides, 11, 167-194, 2014

Hürlimann, M., Copons, R., and Altimir, J.: Detailed debris flow hazard assessment in Andorra: A multidisciplinary approach, Geomorphology, 78, 359-372, 2006.

Hürlimann, M., Rickenmann, D., Medina, V., and Bateman, A.: Evaluation of approaches to calculate debris-flow parameters for hazard assessment, Eng. Geol., 102, 152-163, 2008. 
Hürlimann, M., Abanco, C., Moya, J., and Vilajosana, I.: Results and experiences gathered at the Rebaixader debris-flow monitoring site, Central Pyrenees, Spain, Landslides, 11, 939-953, 2014.

Iverson, R. M.: Landslide triggering by rain infiltration, Water Resour. Res., 36, 1897-1910, 2000.

Jakob, M., Holm, K., Lange, O., and Schwab, J. W.: Hydrometeorological thresholds for landslide initiation and forest operation shutdowns on the north coast of British Columbia, Landslides, 3 , 228-238, 2006.

Keys, H. J. R. and Green, P. M.: Ruapehu Lahar New Zealand 18 March 2007: Lessons for Hazard Assessment and Risk Mitigation 1995-2007, J. Disaster Res., 3, 284-285, 2008.

Kung, H.-Y., Ku, H.-H., Wu, C.-I., and Lin, C.-Y.: Intelligent and situation-aware pervasive system to support debris-flow disaster prediction and alerting in Taiwan, J. Netw. Comput. Appl., 31, 1-18, 2008.

Lee, S.: Application and verification of fuzzy algebraic operators to landslide susceptibility mapping, Environ. Geol., 52, 615-623, 2007.

Lee, S. and Min, K.: Statistical analysis of landslide susceptibility at Yongin, Korea, Environ. Geol., 40, 1095-1113, 2001.

Marchi, L. and Dalla Fontana, G.: GIS morphometric indicators for the analysis of sediment dynamics in mountain basins, Environ. Geol., 48, 218-228, 2005.

Marshall, J. S. and Palmer, W. M.: The Distribution of Raindrops with Size, J. Meteorol. 5, 165-166, 1948.

Medina, V. and Zappa, M.: Rule-based system for FF \& DF forecasting, Report, FP7 project IMPRINTS, 2011.

Medina, V., Bateman, A., and Hürlimann, M.: A 2D finite volume model for debris flow and its application to events occurred in the Eastern Pyrenees, Int. J. Sediment Res., 23, 348-360, 2008.

Mendel, J. M.: Fuzzy-logic systems for engineering: a tutorial, Proceedings of the IEEE, 83, 345-377, 1995.

O'Callaghan, J. F. and Mark, D. M.: The extraction of drainage networks from digital elevation data, Computer Vision, Graphics and Image Processing, 28, 323-344, 1984.

Ortigao, B. and Justi, M. G.: Rio-Watch: the Rio de Janeiro landslide alarm system, Geotechnical News, 22, 28-31, 2004.

Osanai, N., Shimizu, T., Kuramoto, K., Kojima, S., and Noro, T.: Japanese early-warning for debris flows and slope failures using rainfall indices with Radial Basis Function Network, Landslides, 7, 325-338, 2010.

Papa, M. N., Medina, V., Ciervo, F., and Bateman, A.: Derivation of critical rainfall thresholds for shallow landslides as a tool for debris flow early warning systems, Hydrol. Earth Syst. Sci., 17, 4095-4107, doi:10.5194/hess-17-4095-2013, 2013.

Portilla, M., Chevalier, G., and Hürlimann, M.: Description and analysis of the debris flows occurred during 2008 in the Eastern Pyrenees, Nat. Hazards Earth Syst. Sci., 10, 1635-1645, doi:10.5194/nhess-10-1635-2010, 2010.
Raïmat, C., Luis Fonseca, R., Hürlimann, M., Corominas, J., and Fernández, J.: Reconstrucción de la Frecuencia de Corrientes de Derrubios en el Barranc d'Erill, in: VIII Simposio Nacional sobre Taludes y Laderas Inestables, Palma de Mallorca, Spain, 11-14 Junio 2013, 519-529, 2013.

Sánchez-Diezma, R., Sempere-Torres, D., Creutin, J.-D., Zawadzki, I., and Delrieu, G.: An improved methodology for ground clutter substitution based on a pre-classification of precipitaion types, in: 30th International Conference on Radar Meteorology, Munich, Germany, 19-24 July 2001, 271-273, 2001.

Santacana, N., Baeza, B., Corominas, J., De Paz, A., and Marturiá, J.: A GIS-Based Multivariate Statistical Analysis for Shallow Landslide Susceptibility Mapping in La Pobla de Lillet Area (Eastern Pyrenees, Spain), Nat. Hazards, 30, 281-295, 2003.

Schiemann, R., Erdin, R., Willi, M., Frei, C., Berenguer, M., and Sempere-Torres, D.: Geostatistical radar-raingauge combination with nonparametric correlograms: methodological considerations and application in Switzerland, Hydrol. Earth Syst. Sci., 15, 1515-1536, doi:10.5194/hess-15-1515-2011, 2011.

Sempere-Torres, D., Porra, J. M., and Creutin, D.: Characterization of rainfall properties using the drop size distribution: Application to autumn storms in Barcelona, in: International Conference on Cyclones and Hazardous Weather in the Mediterranean Area, Palma de Mallorca, Spain, 14-17 April 1997, 621-628, 1997.

Sterlacchini, S., Ballabio, C., Blahut, J., Masetti, M., and Sorichetta, A.: Spatial agreement of predicted patterns in landslide susceptibility maps, Geomorphology, 125, 51-61, 2011.

Strahler, A. N.: Quantitative Analysis of Watershed Geomorphology, T. Am. Geophysical Union, 38, 913-920, 1957.

Taylor, D. W.: Fundamentals of soil mechanics, John Wiley, New York, USA, 1948.

Unzeta, C.: Disseny d'un sistema d'alerta de corrents d'arrossegalls basat en lògica difusa, B.Eng. thesis, Civil Engineering School, Technical University of Catalonia, Barcelona, Spain, available at: http://crahi.upc.edu/templates/Crahi/php_scripts/getFileDB. php?file_id=2851 (last access: 11 March 2015), 2012.

Velasco-Forero, C. A., Sempere-Torres, D., Cassiraga, E. F., and Gómez-Hernández, J. J.: A non-parametric automatic blending methodology to estimate rainfall fields from rain gauge and radar data, Adv. Water Resour., 32, 986-1002, 2009.

Wieczorek, G. W. and Guzzetti, F.: A review of rainfall thresholds for triggering landslides, 1st Plinius Conference on Mediterranean Storms, Maratea, Italy, 14-16 October 1999, 407-414, 2000.

Wilson, R. C.: The rise and fall of a debris flow warning system for the San Francisco Bay region, California, in: Landslide Hazard and Risk, edited by: Glade, T., Anderson, M. and Crozier, J., John Wiley \& Sons Ltd, Chichester, West Sussex, England, 493-516, 2005. 